\title{
Abrasive and Fretting Wear Resistance of Refractory Cobalt Alloy Specimens Manufactured by the Method of Selective Laser Melting
}

\author{
T. V. Tarasova ${ }^{a}$ *, A. P. Nazarov ${ }^{a}$, and Yu. I. Shalapko ${ }^{b}$ \\ ${ }^{a}$ STANKIN Moscow State University of Technology, Vadkovskii per. 1, Moscow, 127994 Russia \\ ${ }^{b}$ Khmel'nitskii National University, ul. Institutskaya 11, Khmel’nitskii, 29016 Ukraine \\ *e-mail: tarasova952@mail.ru \\ Received May 5, 2014
}

\begin{abstract}
This paper reports the results of comparative studies of the abrasive and fretting wear resistance of specimens manufactured by the method of selective laser melting and casting. The materials of specimens are powdered CoCrMo cobalt refractory alloy and the cast KKhS-D cobalt-based alloy.
\end{abstract}

Keywords: selective laser melting, refractory cobalt alloy, abrasive wear, fretting

DOI: $10.3103 / \mathrm{S} 1068366614050158$

\section{INTRODUCTION}

The essence of selective laser melting (SLM) consists of the alternating deposition of a powder material layer and its melting with a laser beam [1-3]. This technology enables the creation of uniquely shaped articles based on three-dimensional computer models in one technological cycle and eliminates many geometric limitations of consecutive metal working processes, which usually partially reduce the functionality of a part or complicate the process of assembling [4-6]. The use of SLM decreases the time of manufacturing and the primecost of figurine-shaped parts in individual and small lot due to the absence of the special tool creation stage and the reduction of the number of process stages, and the wide spectrum of powder materials and the universality of laser processing provide the possibility of synthesizing new materials and coatings [4-7].

Refractory cobalt-based alloys are a promising powder material $[8,9]$. Figurine-shaped parts manufactured by the SLM method from a powder material based on refractory cobalt alloys may find wide application in aerospace, energetic, and machine-building industries, as well as in the field of fine mechanics [10-12]. New studies of the surface strength characteristics of parts manufactured by the SLM method and the further development of this technology with the purpose of obtaining ensured material properties is an urgent problem of contemporary machine building $[13,14]$.

This work reports the results of studying the abrasive and fretting wear resistance of refractory cobalt alloys obtained by the SLM method. Fretting wear is the mechanical wear of bodies that are in contact under the conditions of small relative tangential displacements [15]. The amplitude of displacements in fretting range from $0.025 \mu \mathrm{m}$ to $0.5 \mathrm{~mm}$. Fretting damages riveted, threaded, splined, keyed, and pinned joints; heavy-shrink fittings of parts; steel ropes, hinges, couplings, springs, valves, electric contact controllers, camshaft mechanisms, helicopter rotor swashplates, and gas turbine engine parts.

The aim of this work is to study the abrasive and fretting wear resistance of specimens manufactured by the SLM method from a refractory cobalt alloy.

\section{MATERIALS AND METHODS}

The selected initial material for manufacturing experimental specimens and parts was refractory CoCrMo alloy powder obtained by gas atomization with the following composition: $\mathrm{Co}, 60-65 \%$; $\mathrm{Cr}, 26-$ 30\%; Mo, 5-7\%; Si, Mn, <1\%; Fe, <0.75\%; C, $<0.16 \%$; $\mathrm{Ni},<0.10 \%$. Figurine-shaped parts and experimental specimens were manufactured at optimal SLM parameters (Table 1) given in [11] on a PTK-PS domestic SLM setup.

The experimental specimens manufactured by SLM were subjected to the following thermal treatment: $5 \mathrm{~h}$ in air at $500^{\circ} \mathrm{C}, 3 \mathrm{~h}$ in air at $730^{\circ} \mathrm{C}$, and $2 \mathrm{~h}$ in vacuum at $1050^{\circ} \mathrm{C}$.

The mechanical properties, such as ultimate tension strength, ultimate yield strength, and relative elongation, were estimated by GOST State Standard 1497-84 on a MTS Insight 100 test machine (MTS Systems Corporation, United States). The impact strength was measured according to GOST (State 
Table 1. Optimal parameters for manufacturing parts by SLM method on PTK-PS setup

\begin{tabular}{c|c|c|c|c|c|c}
\hline $\begin{array}{c}\text { Laser operation } \\
\text { regime/Wavelength, } \\
\mathrm{nm} / \text { Power, W }\end{array}$ & $\begin{array}{c}\text { Shielding } \\
\text { atmosphere }\end{array}$ & $\begin{array}{c}\text { Powder layer } \\
\text { thickness, } \mu \mathrm{m}\end{array}$ & $\begin{array}{c}\text { Scanning } \\
\text { rate, } \mathrm{mm} / \mathrm{s}\end{array}$ & $\begin{array}{c}\text { Laser spot } \\
\text { diameter, } \mu \mathrm{m}\end{array}$ & $\begin{array}{c}\text { Distance between } \\
\text { neighboring } \\
\text { vectors (tracks), } \mu \mathrm{m}\end{array}$ & $\begin{array}{c}\text { Scanning } \\
\text { strategy type }\end{array}$ \\
\hline Continuous/1070/200 & Nitrogen & 50 & 400 & 150 & 100 & Two-zone \\
\hline
\end{tabular}

Table 2. Technical characteristics of the setup for the simulation of low-amplitude fretting

\begin{tabular}{l|l|c}
\hline \multicolumn{1}{c|}{ Characteristic } & Designation & Value \\
\hline Nominal load, N & $P$ & 0100 \\
Oscillation amplitude, $\mu \mathrm{m}$ & $A$ & 130 \\
Oscillation frequency, $\mathrm{Hz}$ & $\mathrm{F}$ & 5100 \\
Dimensions, m & $L \times B \times H$ & $0.8 \times 1.0 \times 1.2$ \\
Weight, kg & $m$ & 550 \\
\hline
\end{tabular}

Standard) $4647-80$ on a Walter and Bai PH 50 test machine (Switzerland). The hardness of experimental specimens was studied by the standard method on an ERCOTEST DIGI 25RS automatic hardness tester.

The abrasive wear resistance was determined on a kaloMAX NT high-sensitive instrument (Germany) in compliance with the scheme shown in Fig. 1a. The counterbody is a steel ball (100Cr6, DIN classification) $30 \mathrm{~mm}$ in diameter. The friction distance was $1400-1500 \mathrm{~m}$, the normal load on the specimen was $0.54 \mathrm{~N}$, and the test time was $30 \mathrm{~min}$. Abrasion suspension was periodically dosed in the region of contact. The result of friction and wear was the formation of a crater on the surface of a specimen (Fig. 1b).

The wear rate was calculated by the formula

$$
V_{r}=\left(\pi h^{2}(3 r-h)\right) /\left(S F_{K}\right),
$$

where $V_{r}$ is the wear coefficient, $\mathrm{m}^{3} /(\mathrm{m} \mathrm{N}) ; h$ is the crater depth, $\mathrm{m} ; r$ is the ball radius, $\mathrm{m} ; S$ is the friction distance, $\mathrm{m}$; and $F_{K}$ is the normal load, N.

The contact interaction of parts manufactured by SLM from CoCrMo alloy powder under the conditions of fretting wear was simulated on a special setup for the fretting wear testing of specimens by the ballplane scheme. The technical characteristics of this setup are given in Table 2, and its principal scheme is shown in Fig. 2.

Counterbody 5 (Fig. 2) shaped as a steel ball (ShKh15, HRC 5961) with a diameter of $12.7 \mathrm{~mm}$ is in contact with the plane of specimen 4 . To provide the maximal vibroinsulation of tested specimen 4, mechanical system 10 was placed on a massive base with a weight of $300 \mathrm{~kg}$. Specimen 4 and strain-gauge beam 3 are fixed on a separate base with a weight of $250 \mathrm{~kg}$.

The setup operates as follows. Specimen 4 is fixed in the clamp of specimen holder 2, and counterbody 5 is placed into holder 8 . Spring 9 creates a normal contact load controlled by a force gauge. Tangential alternating contact loads are created by oscillation generator 10 .

The growth of the relative slip in contact, the wear of a contact spot, and the shape of a hysteresis loop were taken as fretting wear resistance criteria.

To automatize the measurement and recording of tangential microdisplacement oscillograms (recording of signals in certain time intervals), a hardware-software complex consisting of a measuring attachment, a program for controlling the measurement process, and a module for processing the received signals was used.

An analog-to-digital converter based on a K155IP22 integrated microchip and USB of a BM8020 oscillograph was used as a measurement attachment for studies. The measurement instrument based on a K155IP22 integrated microchip provides the simultaneous measurement of the signals from the displacement transducers and the friction force with a rate of 650 measurements per second.

The instrument operates under the control of a special monitoring program. Since a measuring signal must be controlled for a rather long time period, the monitoring program allows the measurements to be (a)

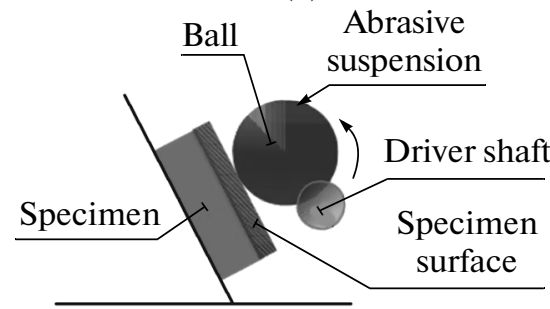

(b)

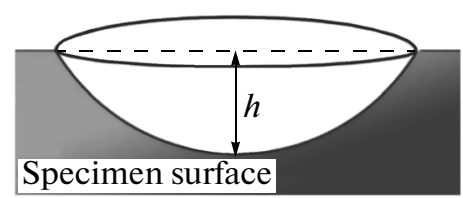

Fig. 1. Scheme of (a) wear resistance testing and (b) crater formed on a tested specimen. 


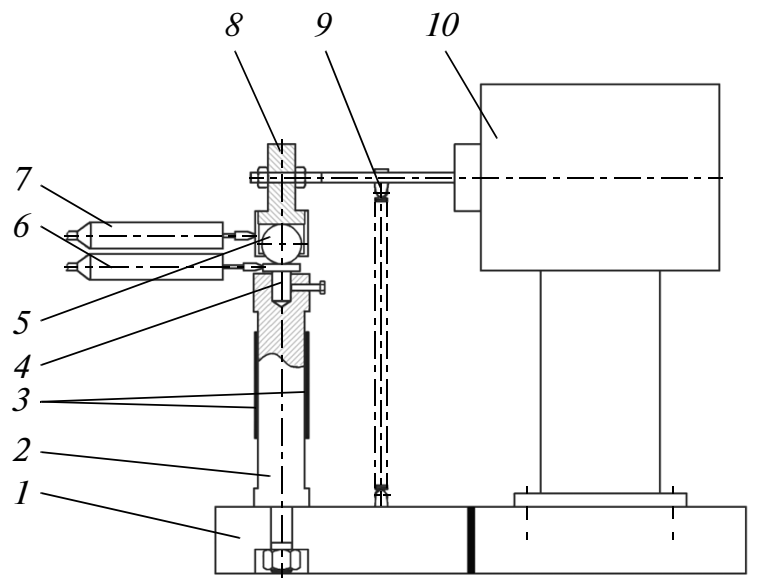

Fig. 2. Principal scheme of the setup for studying the dynamic friction phenomena of low-amplitude fretting: (1) base, (2) specimen holder, (3) strain-gauge transducers, (4) specimen, (5) counterbody, $(6,7)$ microdisplacement transducers, $(8)$ counterbody holder, $(9)$ normal load spring element, and (10) oscillation generator.

performed in different time intervals at different intermeasurement steps. Moreover, recording the input of the signal into a file, the program simultaneously shows input signals on a display. It is possible to show both one and two signals simultaneously. This mode allows for a precise estimation of both the amplitude and shape of a signal, even at the initial stage of testing. The obtained resulting file can be subjected to further processing, which results in its visualization in the regime of both the overlapping of signals and the plotting of a hysteresis loop. The input friction force and relative microdisplacement signals for each channel apart are shown in Fig. 3.

For the friction force-relative microdisplacement curves, the corresponding hysteresis loops were obtained after filtering by two and three points (Fig. 4).

Highly noisy analogous signals were filtered using a fast Fourier transform (FFT). Using FFT, the time series was transited into the frequency region. Higher harmonics are eliminated, after which the time representation of a signal is restored using inverse FFT.

The evolution of destructive phenomena in a nominally fixed friction joint under alternating tangential loading allows the identification of the regimes of contact interaction in a joint and the determination of their time frame [16]. To establish the relation between the dynamic characteristics of a contact and the destruction of a nominally fixed friction joint, the system of fretting process characteristics with the processing of friction hysteresis loops was applied (Fig. 5).

A principal fretting wear characteristic is the slip coefficient $Z$ determined from the formula

$$
Z=\delta_{S} / \delta_{\Sigma}
$$

where $\delta_{S}$ is the amplitude of the displacement of a counterbody (ball) relative to a tested specimen, $\mu \mathrm{m}$, and $\delta_{\Sigma}$ is the total amplitude of the displacement of a counterbody (ball) relative to a tested specimen and a tested specimen under the action of a tangential load relative to its initial position, $\mathrm{m}$.

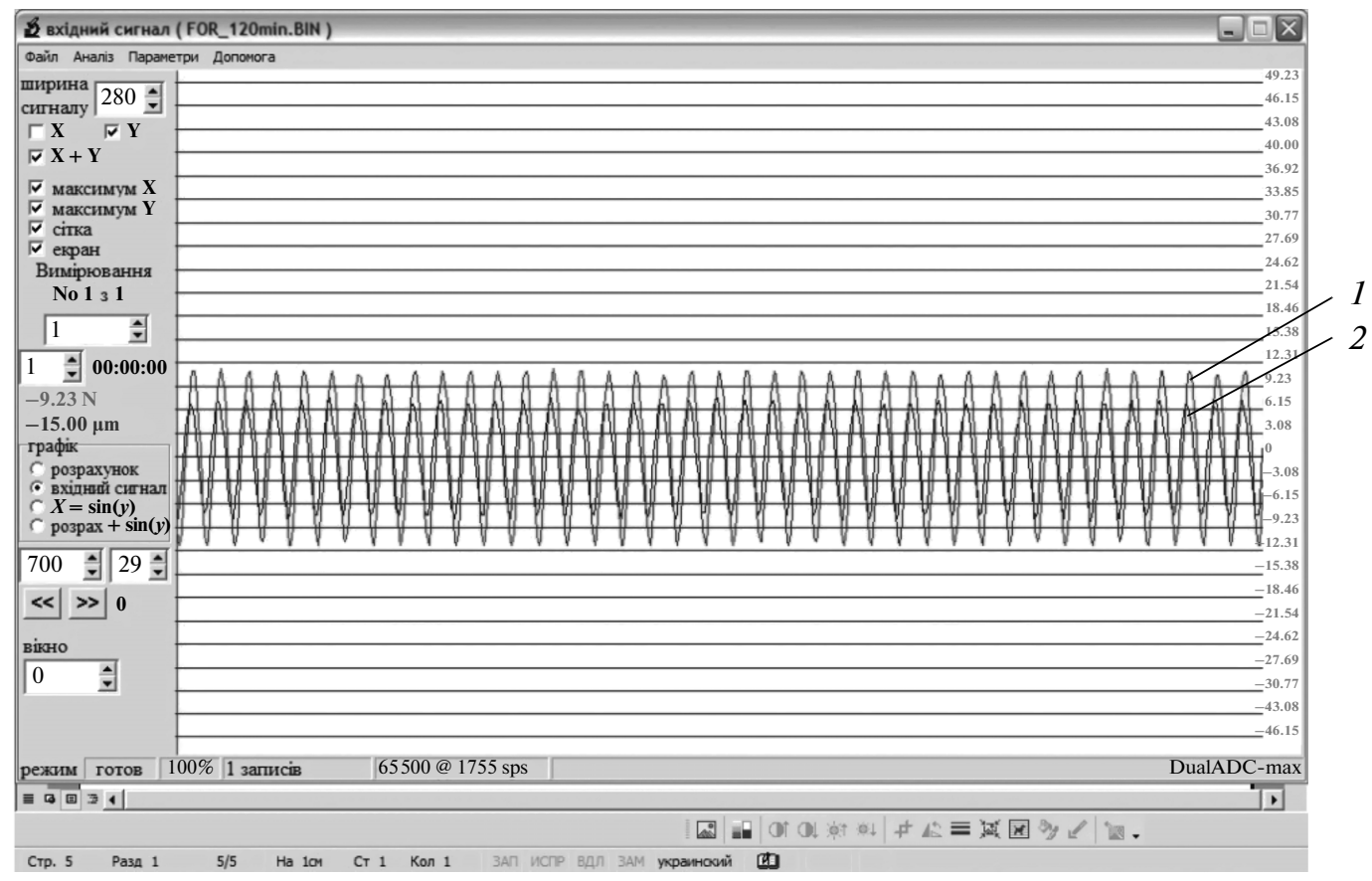

Fig. 3. Main menu of the program for the visualization and processing of signals: (1) displacement curve and (2) friction force curve. 
(a)

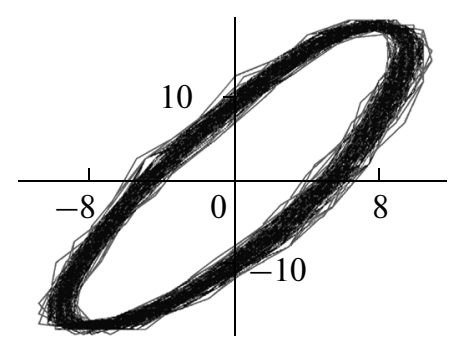

(b)

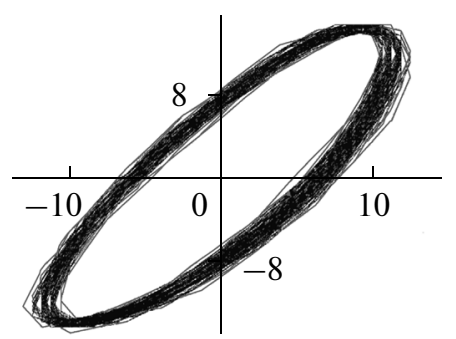

(c)

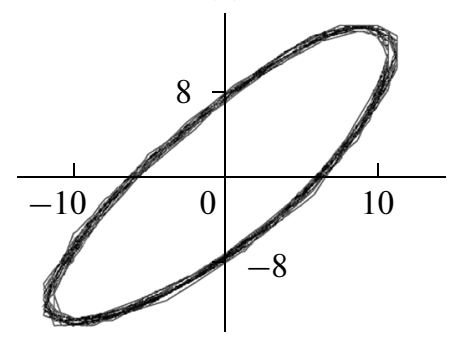

Fig. 4. Plotting of a hysteresis loop:(a) real signal, (b) signal filtered by two points, and (c) signal filtered by three points.

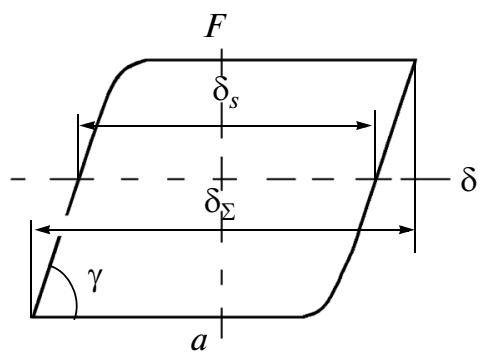

Fig. 5. Hysteresis loop of the fretting process.

It can be seen from Fig. 5 and Eq. (1) that there are no microdisplacements at $Z \rightarrow 0$, and the nominally fixed friction joint is in the absolute stick state, which may be taken as the initial state of conjugated surfaces. During the operation of a joint, destructive fretting processes are developed, the slip amplitude gradually increases, and the contact transits to the global slip regime. In the long run, a nominally fixed friction joint passes to the reciprocal motion regime $(Z \rightarrow 1)$.

The evolution of the hysteresis loops for a nominally fixed friction joint under alternating tangential loading is illustrated in Fig. 6. The slip coefficients for the different operational regimes of a nominally fixed friction joint are given in Table 3.

Table 3. Slip coefficient for the different operational regimes of a nominally fixed friction joint

\begin{tabular}{l|c}
\hline $\begin{array}{c}\text { Operational regime of a nominally } \\
\text { fixed friction joint }\end{array}$ & Slip coefficient \\
\hline Stick regime & $\approx 0$ \\
Partial slip regime & $0-0.2$ \\
Mixed fretting regime & $0.2-0.3$ \\
Dynamic stick-slip regime & $0.3-0.6$ \\
Reciprocal motion regime & Higher than 0.6 \\
\hline
\end{tabular}

\section{RESULTS AND DISCUSSION}

The effect of SLM regimes and further thermal treatment on the physicomechanical properties of experimental specimens has been studied. The results of comparative mechanicals tests are listed in Table 4. The analysis of the obtained data shows that the mechanical characteristics of experimental specimens are much higher than for the cast analogue alloy (except the relative elongation), as is frequently observed for the alloys obtained by laser treatment with infusion [12]. From Table 4 it can also be seen that annealing for $2 \mathrm{~h}$ in vacuum at a temperature of $1050^{\circ} \mathrm{C}$ does not almost produce any effect on the physicomechanical properties of experimental specimens.

The effect of SLM regimes and further thermal treatment on the abrasive wear resistance of specimens manufactured of the cast analogue alloy and by the SLM method is illustrated in Table 5. SLM was performed in the established advantageous regimes (Table 1). It can be seen from Table 5 that the wear rate of SLM specimens is $1.7-1.5$ lower than for the cast analogue alloy and hardly depends on further thermal treatment. Thermal treatment relaxes inner stresses and induces the precipitation of finely dispersed carbides, which increase wear resistance [11]. The appearance of craters formed on the surface of tested specimens is shown in Fig. 7.

The study results obtained in the simulation of the operation of a nominally fixed friction joint make it possible to trace the destructive processes in a contact and to determine the qualitative and quantitative characteristics of a joint from the viewpoint of its integrity.

Typical friction interaction signs appear under the alternating tangential disturbances during the first loading cycles.

As a rule, the situation when slip takes place in discrete interaction zones at the periphery of a contact is typical of the given operational period of a nominally fixed friction joint. At the same time, slip is absent in the majority of actual contact zones. This behavior is explained by the shattering of a contact in some regions, as well as the destruction of counter contact 
(a)

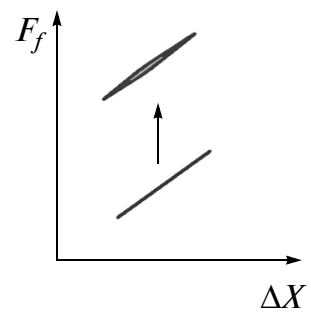

(b)

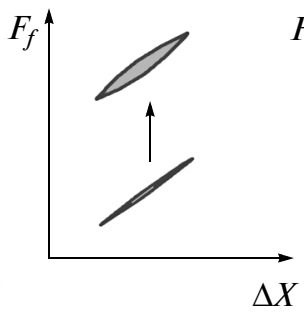

(c)

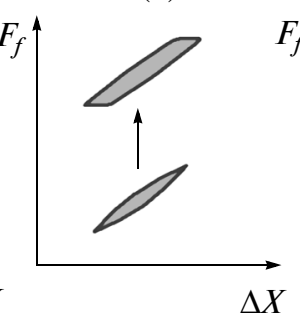

(d)

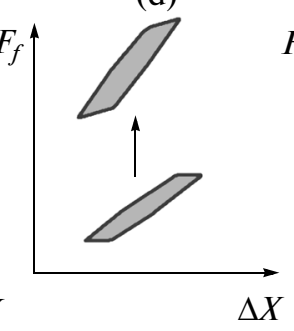

(e)

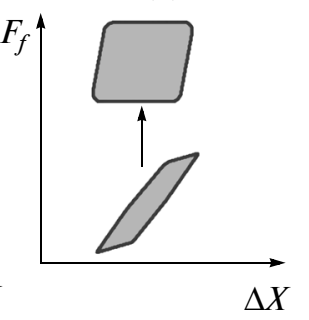

Fig. 6. Global evolution of hysteresis loops: (a) stick regime, (b) partial slip regime, (c) mixed fretting regime, (d) dynamic stickslip regime, and (e) reciprocal motion regime.

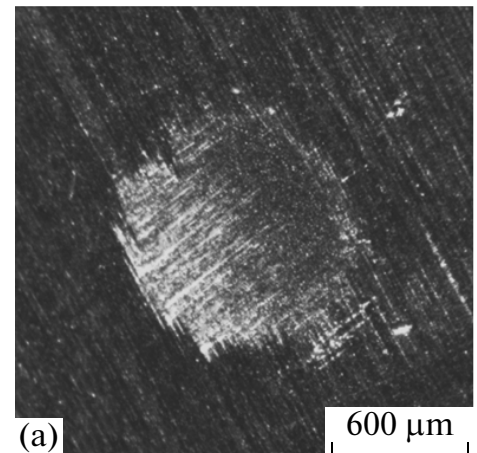

(a)

$600 \mu \mathrm{m}$

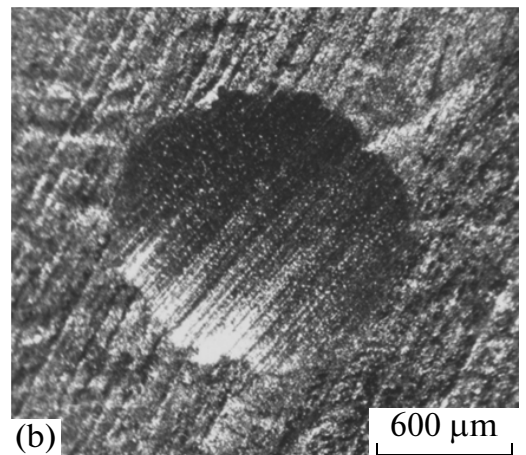

(b) $60 \%$, $600 \mu \mathrm{m}$

Fig. 7. Appearance of craters formed on the surface of tested specimens: (a) SLM specimen (CoCrMo alloy) and (b) cast specimen of an analogue alloy (KKhS-D).

surfaces by a low-amplitude fretting mechanism in the partial slip regime due to the considerable gradation of tangential stresses over the surface of a contact. In this case, slip zones exhibit typical signs of the fretting process, including the presence of powder wear products, the destruction of contact surface layers, and the absence of the withdrawal of wear products from a contact spot.

The further operation of a nominally fixed friction joint under these conditions leads to the surface destruction of a material due to low-amplitude fretting at the periphery of a contact. In zones of maximum tangential stresses and, consequently, the maximum relative displacements, the accumulation of wear products takes place and, as a result, the effective contact surface area decreases. The load-bearing surface area decreases in proportion to a decrease in the effective contact surface area. The occurrence of these processes indicates the transition from the partial slip regime to the mixed fretting regime (Fig. 8).

In the mixed fretting regime, the oxidation and destruction of physicomechanical bonds occur in the slip zone, whereas the destruction in the stick zone proceeds due to the cyclic elastoplastic straining by a low-cycle contact fatigue mechanism. The destruction of local sites is accompanied by the formation of metal oxides and the adsorption of water molecules from the air. The volume of these products exceeds the volume

Table 4. Mechanical characteristics of the cast KKhS-D alloy and the specimens manufactured by the SLM method on a PTK-PS setup

\begin{tabular}{l|c|c|c|c|c}
\hline \multicolumn{1}{|c|}{ Characteristic } & $\begin{array}{c}\text { Ultimate yield } \\
\text { strength } \sigma_{0.2}, \\
\mathrm{MPa}\end{array}$ & $\begin{array}{c}\text { Ultimate } \\
\text { strength } \sigma_{\mathrm{B}}, \mathrm{MPa}\end{array}$ & $\begin{array}{c}\text { Relative } \\
\text { elongation } \delta, \%\end{array}$ & $\begin{array}{c}\text { Impact strength } \\
\mathrm{KCU}, \mathrm{J} / \mathrm{cm}^{2}\end{array}$ & $\begin{array}{c}\text { Hardness, } \\
\mathrm{HRC}\end{array}$ \\
\hline $\begin{array}{l}\text { SLM, CoCrMo powder } \\
\text { (without thermal treatment) }\end{array}$ & $1050 \pm 150$ & $1300 \pm 150$ & No less than 6 & $21 \pm 1$ & $42 \pm 4$ \\
\hline $\begin{array}{l}\text { SLM, CoCrMo powder } \\
\left(2 \mathrm{~h} \text { in vacuum at } 1050^{\circ} \mathrm{C}\right)\end{array}$ & $1000 \pm 150$ & $1250 \pm 150$ & No less than 6 & - \\
\hline $\begin{array}{l}\text { Casting, KKhS0-D } \\
\text { (without thermal treatment) }\end{array}$ & $600 \pm 50$ & $850 \pm 50$ & No less than 7.5 & - & $34 \pm 2$ \\
\hline
\end{tabular}


Table 5. Wear rate for the KKhS-D alloy specimens manufactured by the SLM method on a PTK-PS setup and by casting

\begin{tabular}{l|c|c|c|c}
\hline \multicolumn{2}{c|}{ Thermal treatment } & $\begin{array}{c}\text { Without thermal } \\
\text { treatment }\end{array}$ & $3 \mathrm{~h}$ in air at $730^{\circ} \mathrm{C}$ & $\begin{array}{c}2 \mathrm{~h} \text { in vacuum } \\
\text { at } 1050^{\circ} \mathrm{C}\end{array}$ \\
\cline { 1 - 4 } SLM, CoCrMo powder & $\begin{array}{c}\text { Wear rate } \times 10^{-15} \\
\mathrm{~m}^{3} /(\mathrm{m} \mathrm{N})\end{array}$ & $3.1 \pm 0.2$ & $3.4 \pm 0.2$ & $3.3 \pm 0.2$ \\
\cline { 1 - 4 } Cast KKhS-D & $5.4 \pm 0.3$ & $5.1 \pm 0.3$ & $5.2 \pm 0.3$ \\
\hline
\end{tabular}

of the destructed material, which increases the pressure in a contact. Metal oxide particles in the intercontact space are converted into dense, solid clusters that act as an abrasive in the presence of free metallic zones with a further increase in the normal pressure due to the accumulation of wear products.

From the viewpoint of dynamics, the transition of a contact pair from the partial slip regime to the mixed fretting regime and, in the long run, to the dynamic stick-slip regime is characterized by a certain friction force lag (Fig. 9a). This lag is due to the nonelastic phenomena in the contact and destructive processes (Fig. 9b).

The further evolution of destructive processes in a nominally fixed friction joint causes the ratio of the sizes of stick and slip zones to approach a certain critical value at which the moment of slip over the entire contact spot occurs. This state is characterized by dynamic contact variability, at which the smallest change in any parameter leads to the transition to the dynamic stick-slip regime. In contrast to the mixed fretting regime, which is always observed within a contact spot, the contact friction becomes a principal characteristic for the dynamic stick-slip regime. The boundaries of the dynamic stick-slip regime are considered to be such that the displacements of surfaces are comparable with the elastoplastic strain of a contact, but its size is smaller than the contour of the contact spot.

As the load in a contact further grows, the relative displacements also increase with the simultaneous destruction of surface asperities. As the number of loading cycles is gradually increased, the size of the contact spot grows in the direction of slip, until the
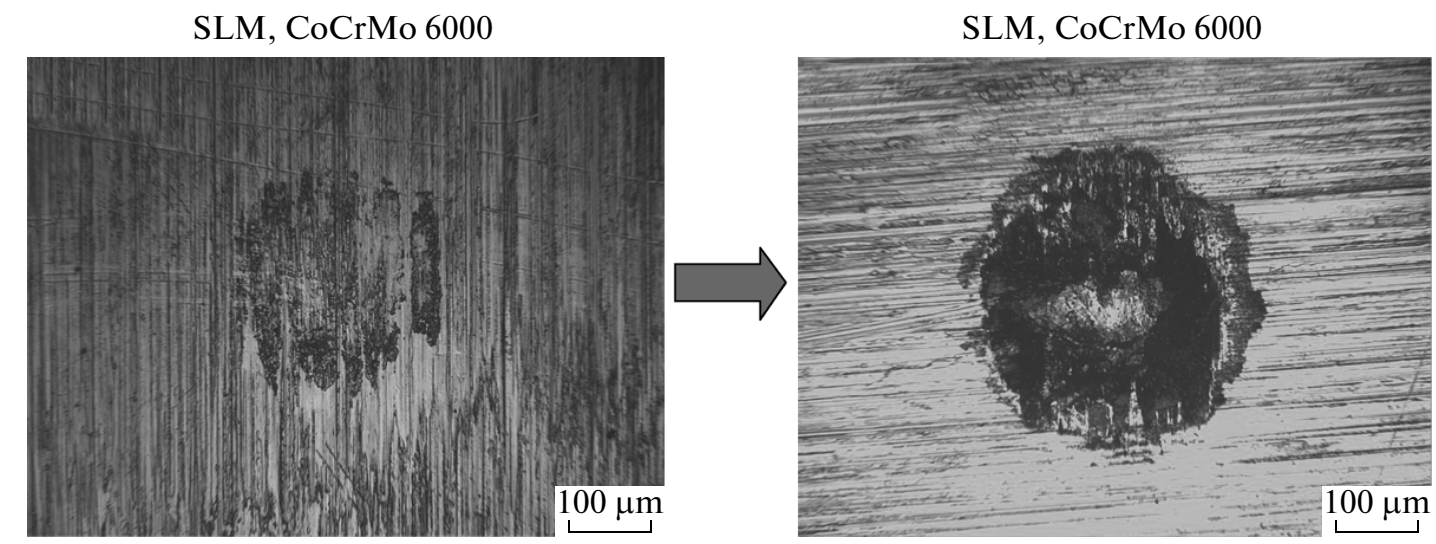

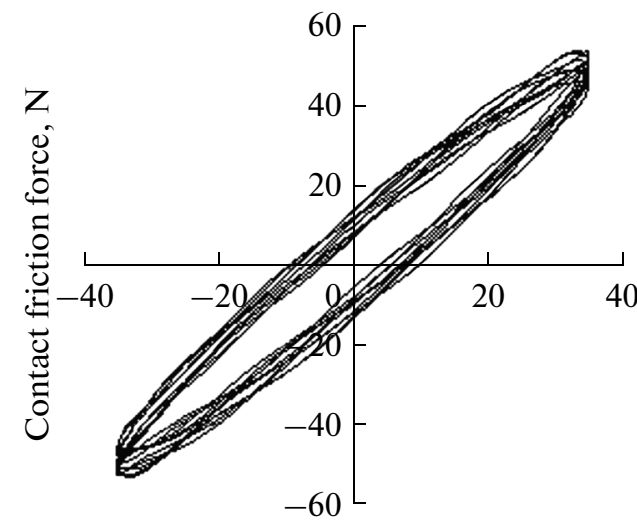

Relative displacement, $\mu \mathrm{m}$

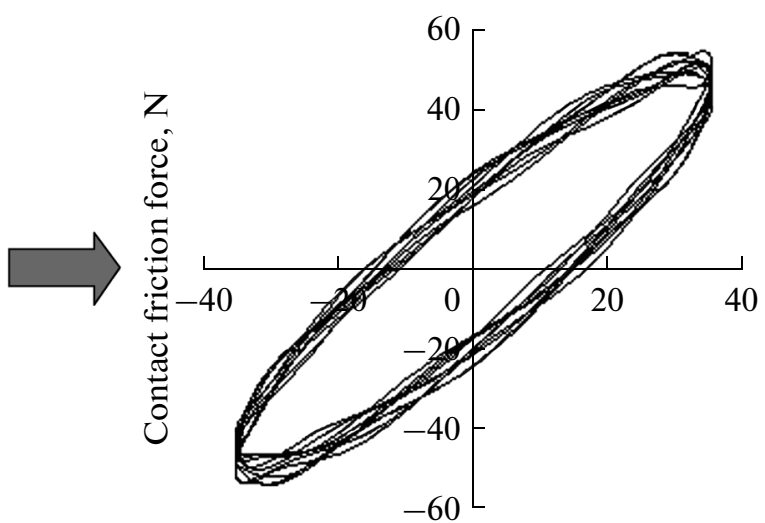

Relative displacement, $\mu \mathrm{m}$

Fig. 8. Transition processes in a contact spot during the passage from the partial slip regime to the mixed fretting regime ("ballplane" contact scheme; tangential load, $40 \mathrm{~N}$; normal load, $60 \mathrm{~N}$; disturbance frequency, $100 \mathrm{~Hz}$ ). 
(a)

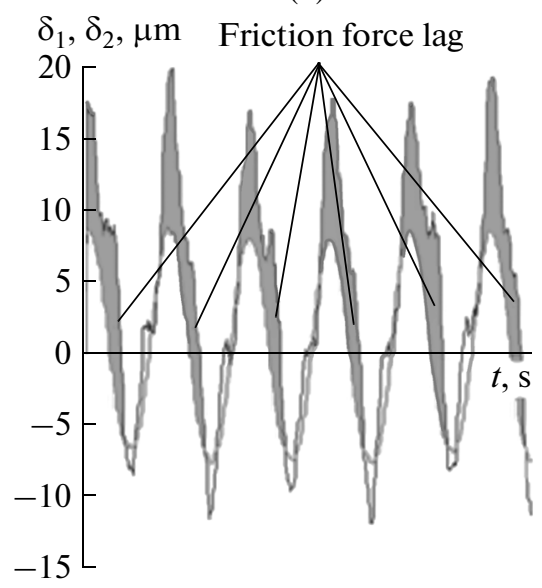

(b)

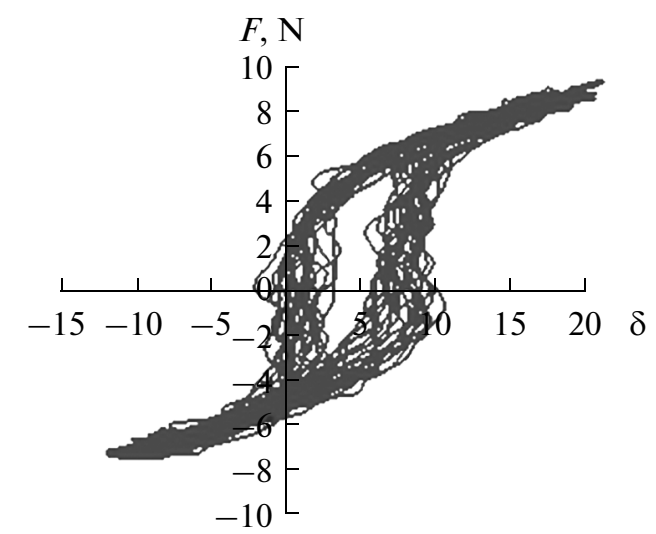

Fig. 9. Dynamic detection of transitions between the operational regimes of a nominally fixed friction joint: (a) oscillograms of the transition from the partial slip regime to the mixed fretting regime and (b) typical friction hysteresis.

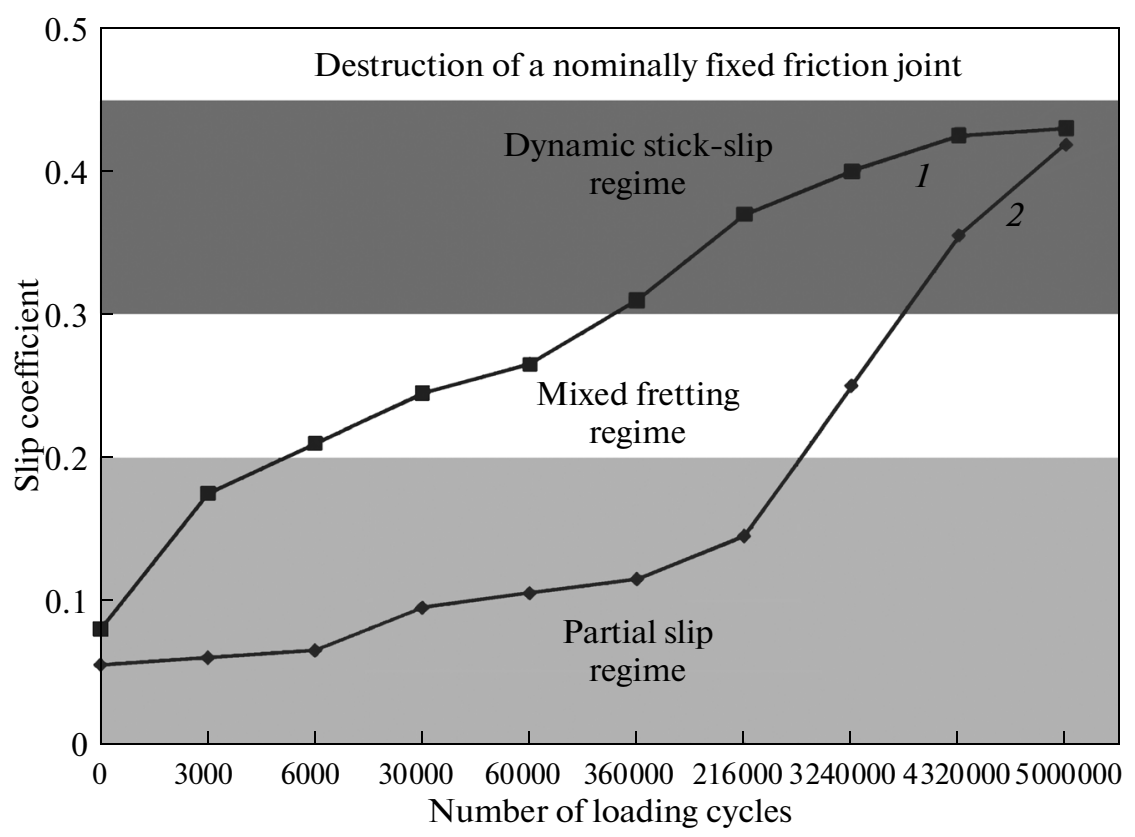

Fig. 10. Kinetics of the destruction of a nominally fixed friction joint: (1) SLM (CoCrMo alloy) and (2) casting (KKhS-D analogue alloy).

moment when the strained contact spot completely displaces from its original zone. The intensive withdrawal of wear products from a contact zone occurs with the loss of the character of rigid fitting and the destruction of a joint from the viewpoint of its functionality.

The results of the comparative kinetic tests of the destruction of a nominally fixed friction joint are shown in Fig. 10.

The cast analogue alloy (Fig. 10) has a lower slip coefficient at a number of loading cycles below 360000 . However, the slip coefficient of the cast ana- logue alloy begins to abruptly grow after 360000 cycles of loading and becomes equal to the slip coefficient of the CoCrMo alloy obtained by the SLM method at 5000000 cycles of loading. This phenomenon is explained by the fact that the hardness of the analogue alloy is nearly $10 H R C$ lower than for the CoCrMo alloy (36 HRC against $46 H R C$ ), which leads to tighter contact between a cast analogue alloy specimen and a counterbody at a nominal load of $60 \mathrm{~N}$. The lower hardness of the analogue alloy manifest itself later, and the slip coefficient begins to abruptly grow, especially in the mixed fretting and dynamic stick-slip regimes 


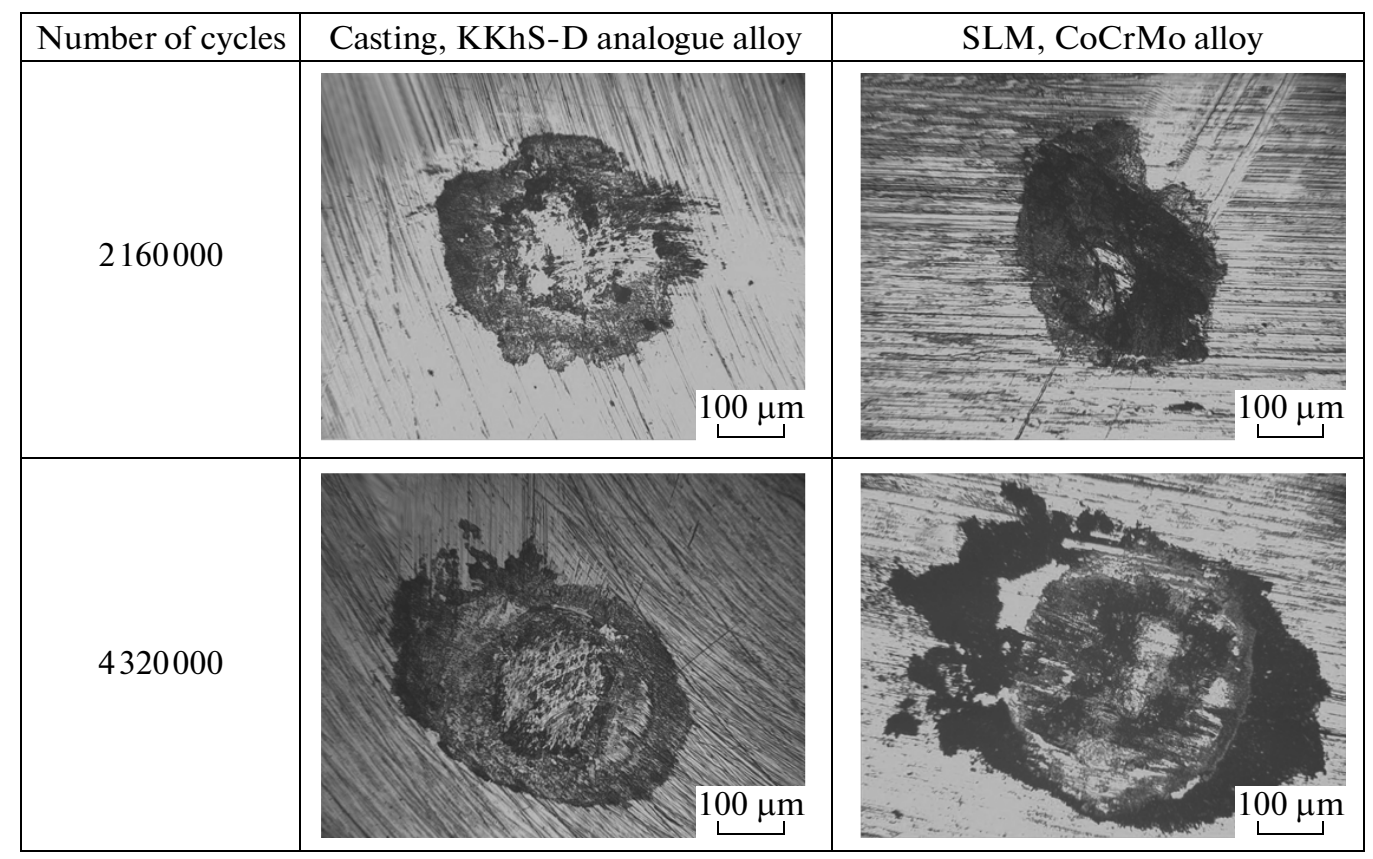

Fig. 11. Evolution of destructive processes in the contact spot of a nominally fixed friction in fretting wear at a number of loading cycles of 216000-4320000.

(Fig. 10) and becomes equal to the slip coefficient of the SLM CoCrMo alloy at 5000000 cycles. However, the results of the transition of the analogue alloy to global slip are more disastrous by both the wear and slip criteria. This is explained by the accumulation of contact fatigue phenomena during the period of nominal stick (to four million cycles) and local seizure at the stage of the transition to slip (Fig. 11). Hence, the increase of the fretting wear resistance of parts manufactured by the SLM method from the CoCrMo alloy will have the most pronounced effect during long-term operation. The given result obtained at a fixed tangential load of $40 \mathrm{~N}$ and a normal load of $60 \mathrm{~N}$ and is rather critical to the change in the normal load. It should be noted that the structure of the material obtained by the SLM method at a certain normal load has considerable dissipative properties, which are especially pronounced at a load of $60 \mathrm{~N}$. The expansion of the normal load range as a leading factor that provides the integrity of the joint during the installation of a structure or the assembling of joints is an important SLM engineering problem in ensuring the fretting wear resistance of the surface layers.

Hence, the parts manufactured from CoCrMo alloy using the SLM method can be recommended for operation under fretting conditions, since the resource of these parts under fretting conditions at a tangential load of $40 \mathrm{~N}$ and a normal load of $60 \mathrm{~N}$ is 5000000 cycles.

The evolution of destructive processes in the contact spot of a nominally fixed friction joint under fretting wear conditions is illustrated in Fig. 11.

\section{CONCLUSIONS}

The advantageous SLM regimes determine the following characteristics of manufactured experimental specimens: the density $\rho=8.3 \pm 0.1 \mathrm{~g} / \mathrm{cm}^{3}$, the hardness is $42 \pm 4 \mathrm{HRC}$, the linear size precision is $\pm 0.06 \mathrm{~mm}$, the surface roughness $R_{a}=8 \pm 2 \mu \mathrm{m}$, the ultimate yield strength $\sigma_{0.2}=1000 \pm 150 \mathrm{MPa}$, the ultimate strength $\sigma_{\mathrm{B}}=1250 \pm 150 \mathrm{MPa}$, the relative elongation is no less than $\sigma=6 \%$, and the impact strength $\mathrm{KCU}$ is $21 \pm 1 \mathrm{~J} / \mathrm{cm}^{2}$. This enables figurine-shaped parts to be manufactured for operation under high mechanical loads.

Comparative wear-resistance tests show that the wear coefficient of the SLM specimens is 1.71.5 times lower than for the cast analogue alloy specimens and equals $(3.3 \pm 0.2) \times 10^{-15} \mathrm{~m}^{3} /(\mathrm{m} \mathrm{N})$. The wear coefficient of the SLM specimens hardly depends on further thermal treatment. Hence, the developed engineering process can be recommended for the manufacturing of figurine-shaped parts operated under the conditions of increased wear and high temperatures.

The fretting wear resistance of the SLM specimens is highly competitive with the wear resistance of the cast analogue alloy specimens. At five million cycles, their slip value becomes the same as for the KKhS-D analogue alloy. The SLM specimens demonstrate a greater slip and a smaller contact spot wear, and the analogue alloy exhibits a higher surface damageability in long-term fretting tests. At five million cycles, the 
slip value becomes the same as for the $\mathrm{KKhS}-\mathrm{D}$ analogue alloy.

\section{ACKNOWLEDGMENTS}

This work was supported by the Ministry of Science and Education of the Russian Federation within the framework of state task in the sphere of scientific activity.

\section{DESIGNATION}

SLM — selective laser melting

\section{REFERENCES}

1. Shishkovskii, I.V., Lazernyi sintez funktsional'no-gradientnykh mezostruktur i ob"emnykh izdelii (Laser Synthesis of Functionally-Gradient Mesostructures and Bulk Articles), Moscow: Fizmatlit, 2009.

2. Gibson, I., Rosen, D.W., and Stucker, B., Additive Manufacturing Technologies: Rapid Prototyping to Direct Digital Manufacturing, New York: Springer-Verlag, 2009.

3. Yadroitsev, I., Bertrand, P., Antonenkova, G., Grigoriev, S., and Smurov, I., Use of track/layer morphology to develop functional parts by selective laser melting, J. Laser Appl., 2013, vol. 25, Article Number: UNSP 052003.

4. Fominski, V.Y., Grigoriev, S.N., Romanov, R.I., Zuev, V.V., and Grigoriev, V.V., Properties of tungsten oxide thin films formed by ion-plasma and laser deposition methods for MoSiC-based hydrogen sensors, Semiconductors, 2012, vol. 46, pp. 401-409.

5. Tarasova, T.V. and Shalapko, Yu.I., Processes of dynamics of surface layers during low-amplitude fretting, J. Friction Wear, 2013, vol. 34, pp. 166-174.

6. Tarasova, T.V., Gvozdeva, G.O., and Tikhonova, E.P., Prospects of laser radiation use for non-ferrous alloy surface treatment, Vestn. Mos. Gos. Tekhn. Univ. Stankin, 2012, no. 2 pp. 140-143.
7. Grigor'ev, S.N., Tarasova, T.V., Gvozdeva, G.O., and Nowotny, S., Micro-laser facing of Al-Si system alloys, Metal Sci. Heat Treat., 2013, vol. 55, pp. 242-246.

8. Grigoriev, S.N., Fominskii, V.Yu., and Gusarov, A.V., Features of micro- and nanostructures of $\mathrm{Au}-\mathrm{Ni}$ alloys obtained on nickel due to different modes of pulse laser alloying, Metal Sci. Heat Treat., 2012, vol. 54, pp. 34-40.

9. Grigoriev, S.N., Romanov, R.I., and Fominskii, V.Yu., Dependence of mechanical and tribological properties of diamond-like carbon coatings on laser deposition conditions and alloying by metals, J. Friction Wear, 2012, vol. 33, pp. 253-259.

10. Fominskii, V.Y., Romanov, R.I., Grigoriev, S.N., and Nevolin, V.N., Effect of the pulsed laser deposition conditions on the tribological properties of thin-film nanostructured coatings based on molybdenum diselenide and carbon, Tech. Phys., 2012, vol. 57, pp. 516523.

11. Tarasova, T.V. and Nazarov, A.P., Study of the process of selective laser melting of refractory cobalt alloys, Vestn. Mos. Gos. Tekhn. Univ. STANKIN, 2013, no. 2, pp. 17-21.

12. Tarasova, T.V. and Popova, E.V., Formation of coatings by a method of overlay laser welding of powders of titanium and silicon carbide on a surface of low-carbon steel, Metallofiz. Nov. Tekhnol., 2013, vol. 35, pp. 1487-1500.

13. Tarasova, T.V., Prospects of the use of laser radiation for raising the wear resistance of corrosion-resistant steels, Metal Sci. Heat Treat., 2010, vol. 52, pp. 284-288.

14. Kumar, S. and Kruth, J.-P., Wear performance of SLS/SLM materials, Adv. Eng. Mater., 2008, vol. 10, pp. 1-4.

15. Pupo, Y., Delgado, J., Sereno, L., and Ciurana, J., Scanning space analysis in selective laser melting for CoCrMo powder, Procedia Eng., 2013, vol. 63, pp. 370-378.

16. Gura, G.S., Kachenie tel s treniem. Fretting (Fretting) Sochi: Doriya, 2009.

17. Shalapko, Ju. and Radek, N., Dynamic motion into contact with microslip. Surface observation, experiment and simulation, Technolog, 2011, no. 2, pp. 15-20.

Translated by E. Glushachenkova 